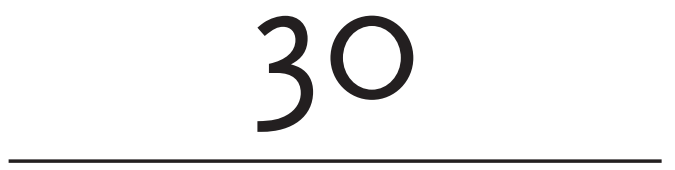

\title{
BOARD SUPPORT
}

\author{
Siobhan Lavery
}

Boardrooms are the domain of a stellar cast of people representing many varied and important roles, such as chair, executive director, non-executive director (NED), chief financial officer, investment manager, chief information officer, legal counsel, and auditor, to name but a few. Amongst this ensemble the company secretary can be overlooked and erroneously deemed by some to play only a minor role operating in the shadows; however, the role of the company secretary is fundamental to the smooth and efficient running of the board and in turn the organisation.

No two boards are the same, and even those of a similar size, operating in a similar sector, with a similar structure will have different boardroom dynamics. This means that the demands on the company secretary and the variety of functions they may undertake will vary accordingly; however, the importance of the role is unchanged. The company secretary is often a trusted adviser with key responsibility for ensuring compliance with laws and regulation.

Who fulfils the role of company secretary can also be diverse. It may be undertaken by the legal counsel, may comprise of an in-house team DOI: $10.4324 / 9781003201182-36$ 
of individuals, may be outsourced to a third-party provider, or the duties may even be undertaken by a director of the organisation. However, for the purposes of this chapter it is assumed that the board has appointed an appropriately qualified company secretary who is conversant in the rules and regulations that apply to the organisation, sector, and jurisdiction.

The vast majority of a company's secretary's work is undertaken behind the scenes, outside of the boardroom. A good company secretary will make the organisation and completion of various tasks appear seamless, belying the hard work that has been required. The corollary is that, as the focus of a board is rarely fully on a company secretary and the majority of their workload is completed in the background, if there are any deficiencies with that workload being carried out, they can take a long time to come to the board's attention.

Qualified company secretaries have undertaken years of study and passed numerous exams to obtain their qualification. By their nature they should be dedicated and intent on acting with integrity. Following are some characteristics and questions that should apply to all company secretaries, regardless of the organisation or sector in which they work.

\section{Archivist}

It has often been said that the company secretary is the "conscience of the company"; however, in fact a key function of a company secretary is to act as the memory of the company by maintaining and storing all the company documents. These range from those required under law (statutory registers), to those required for compliance with regulation and the smooth running of the organisation (policies and procedures), to those that are useful to keep for corporate memory (general correspondence).

For a NED, the company secretary is usually the only source of this material; therefore, it is vitally important to obtain comfort that the documents are being maintained and kept up to date in a proper, efficient, and easily accessible manner.

Questions to Ask:

- Are all applicable statutory registers being maintained and being kept up to date?

- What policies and procedures are in place? 
- Does the organisation have in place all the policies and procedures which it is required by law or regulation, or best practice, to have in place?

- How are key documents stored and what measures have been put in place to avoid their accidental destruction (that is, the use of a fireproof safe for hard copy documents, regular back-up of soft copy documents, IT security measures of the system on which on the documents are stored)?

\section{Coordinator extraordinaire}

A fundamental function of the company secretary is the coordination of board meetings. As mentioned, a boardroom comprises a variety of people, and a board meeting requires not only the alignment of the diaries of a cast of many, but the practical arrangements of the meeting itself (booking a room, arranging for catering, obtaining any necessary IT equipment), and the timely provision and distribution of papers ahead of the meeting. This requires key planning and multitasking skills, and must be completed to a high standard to ensure the effective and efficient running of the board meeting.

When coordinating with a number of different parties, there are many things that are outside of a company secretary's control - the director who asks for a board meeting time or date or even venue to be changed at the last minute, an adviser who does not provide their papers for the board pack until after the deadline provided, the piece of IT equipment that suddenly fails. Therefore, the company secretary should always be methodically planning ahead.

- Are the board meetings scheduled with sufficient notice and sufficient frequency?

- Have calendar invitations been sent to all participants, and are the details contained in the invitation up to date?

- Has the agenda been circulated for comment sufficiently in advance of the meeting?

- Have the timings of the agenda items and attendees been agreed in advance with the chair and communicated to the appropriate parties? 
- Are the board papers and other documents requiring board review distributed in a timely manner?

Another aspect of coordination that often falls within the purview of the company secretary is the submission of various legal and regulatory returns and completion of organisation-specific tasks within set deadlines. These can be numerous, and the failure to meet them can often incur fines or possibly reputational damage. Further, in a world of continual ever-changing laws and regulations, it often falls to the company secretary to bring these to the attention of the board and to coordinate with other advisers to ensure the organisation's compliance with any new requirements.

- Is there a schedule tracking the deadlines the board and organisation must comply with throughout the year, and who is responsible for the completion of those tasks?

- Who is responsible for keeping up to date with regulatory or other changes which may impact the organisation during the course of the year?

\section{Diplomat}

A boardroom can contain challenging and demanding characters. An effective company secretary needs to know how to interact with all personalities diplomatically to ensure that they are always viewed as professional, accessible, and impartial by all directors and stakeholders.

- Is the company secretary deemed to be accessible and impartial by all directors and stakeholders?

\section{Scribe}

The most well-known function of a company secretary's role is that of minute-taker. Under law, minutes are deemed to be evidence of the proceedings at the meeting, and various court cases have highlighted the vital importance of accurate minutes. Whilst every board will spend time at each meeting discussing minutes, poor practices such as minutes not being 
circulated for review sufficiently in advance, comments not being provided in a timely manner, and finalised minutes not being signed, can result in an incomplete minute book.

- Are the minutes accurate and of high quality?

- Are the minutes circulated within an appropriate time period after the meeting?

- Does the final version of the minutes tabled for signing contain all directors' comments and amendments?

- Has the final version been signed and returned to the company secretary and filed appropriately?

\section{Succession}

There has rightly been much focus on boards devising and implementing orderly succession plans; however, there is rarely any focus on the succession plan for the company secretary. As previously noted, there is great diversity in who fulfils the role of company secretary; however, often the function is carried out by just one individual, which can lead to a significant risk for an organisation in the event of a resignation or injury or simply a lack of efficient communication.

- Who will undertake the company secretarial duties in the event of a sudden absence/departure of the current company secretary?

- Is the replacement company secretary sufficiently experienced and knowledgeable about the organisation and its requirements?

- Does the replacement company secretary have the requisite resources and support to step into the role? 